\title{
Perioperative Plasma Neutrophil Gelatinase-Associated Lipocalin Measurement in Patients Who Undergo Left Ventricular Assist Device Implantation Surgery
}

\author{
Maki Sumida, MD; Kent Doi, MD, PhD; Osamu Kinoshita, MD, PhD; \\ Mitsutoshi Kimura, MD, PhD; Minoru Ono, MD, PhD; Yoshifumi Hamasaki, MD, PhD; \\ Takehiro Matsubara, MD, PhD; Takeshi Ishii, MD, PhD; Naoki Yahagi, MD, PhD; \\ Masaomi Nangaku, MD, PhD; Eisei Noiri, MD, PhD
}

Background: Perioperative complication of end-organ injury including acute kidney injury (AKI) is a frequent and
severe problem for patients undergoing left ventricular assist device (LVAD) implantation. This study evaluated an
emerging AKI biomarker, plasma neutrophil gelatinase-associated lipocalin (NGAL), in a LVAD implantation cohort.

Methods and Results: Of 31 LVAD implantation patients enrolled to this study, 17 (55\%) patients were diagnosed as having AKI. Six AKI patients showed severe AKI requiring renal replacement therapy (RRT). Plasma NGAL values in the AKI-with-RRT group $(n=6)$ were significantly higher than that in other patients, although the AKI-withoutRRT ( $n=11$ ) group showed a similar level of plasma NGAL to that of the non-AKI group $(n=14)$. Multiple logistic regression analysis revealed that plasma NGAL measured at pre-operation and central venous pressure at pre-operation and $12 \mathrm{~h}$ after surgery independently discriminated against postoperative RRT requirement. In the AKI-with-RRT group, plasma NGAL decreased before termination of RRT in 4 patients who eventually showed renal recovery, although no decline of plasma NGAL was observed in 2 patients who showed no recovery of renal function. Removal of blood NGAL by continuous hemodiafiltration was shown to be $70-75 \%$ lower than that of creatinine.

Conclusions: Measurement of perioperative plasma NGAL is useful for predicting severe AKI requiring RRT and renal recovery in patients who have had LVAD implantation surgery. Further investigation is necessary to confirm these findings because this study examined a low number of patients. (Circ $J$ 2014; 78: 1891-1899)

Key Words: Acute kidney injury; Biomarker; Left ventricular assist device; Neutrophil gelatinase-associated lipocalin

$\mathbf{L}$ eft ventricular assist device (LVAD) implantation has been used as a bridge to transplantation or destination therapy for patients with end-stage heart failure because mechanical circulatory support has recently been demonstrated as better than medication. ${ }^{1}$ According to data from the Interagency Registry for Mechanically Assisted Circulatory Support (INTERMACS), ${ }^{2}$ a total of 6,561 heart failure patients received LVADs during 2006-2012 in the US. Their respective 1-year and 2-year survival rates were approximately $80 \%$ and $70 \%$. Although LVAD implantation can improve hemodynamics and end-organ function including renal dysfunction, 3,4 perioperative renal dysfunction is significantly associated with poor outcomes after LVAD implantation. ${ }^{3-7}$ Notably, severe renal dysfunction that required renal replacement therapy (RRT) near the time of implantation was significantly associated with a much lower early survival. ${ }^{2}$

Acute kidney injury (AKI) is a severe complication affecting patients who undergo cardiac surgery. Even slight serum creatinine (Cre) changes during the postoperative period increased mortality in a large cardiac surgery cohort. ${ }^{8}$ However, the limitations of serum Cre for the early detection and accurate estimation of renal injury in AKI are well known. ${ }^{9}$ New AKI biomarkers such as neutrophil gelatinase-associated lipocalin (NGAL), interleukin-18 (IL-18), kidney injury molecule-1 (KIM-1), and L-type fatty acid-binding protein (L-FABP) have been studied intensively in recent years. ${ }^{10-13}$ Plasma NGAL

Received January 20, 2014; revised manuscript received April 14, 2014; accepted April 27, 2014; released online June 13 , 2014 Time for primary review: 38 days

Department of Nephrology and Endocrinology (M.S., M.N., E.N.), Department of Emergency and Critical Care Medicine (K.D., T.M., T.I., N.Y.), Department of Cardiothoracic Surgery (O.K., M.K., M.O.), 22nd Century Medical and Research Center (Y.H.), The University of Tokyo, Tokyo; Japan Science and Technology Agency/Japan International Cooperation Agency (JST/JICA), Science and Technology Research Partnership for Sustainable Development (SATREPS), Tokyo (E.N.), Japan

Mailing address: Kent Doi, MD, PhD, Department of Emergency and Critical Care Medicine, University Hospital, The University of Tokyo, 7-3-1 Hongo, Bunkyo-ku, Tokyo 113-8655, Japan. E-mail: kdoi-tky@umin.ac.jp

ISSN-1346-9843 doi:10.1253/circj.CJ-14-0008

All rights are reserved to the Japanese Circulation Society. For permissions, please e-mail: cj@j-circ.or.jp 


\begin{tabular}{|c|c|c|c|}
\hline & \multicolumn{3}{|c|}{ Group } \\
\hline & Non-AKI $(n=14)$ & AKI-without-RRT ( $n=11)$ & AKI-with-RRT $(n=6)$ \\
\hline & \multicolumn{3}{|c|}{ Pre-operative data } \\
\hline Age (years) & 39 [32-51] & $41[36-50]$ & 48 [34-62] \\
\hline Male, n (\%) & $12(86)$ & $9(82)$ & $4(67)$ \\
\hline \multicolumn{4}{|l|}{ Etiology, n (\%) } \\
\hline Ischemic heart disease & $1(7)$ & $2(18)$ & $2(33)$ \\
\hline DCM & $11(79)$ & $8(73)$ & $1(17)^{\#}$ \\
\hline $\mathrm{HCM}$ & $1(7)$ & $0(0)$ & $2(33)$ \\
\hline Myocarditis & $1(7)$ & $1(9)$ & $1(17)$ \\
\hline \multicolumn{4}{|l|}{ Hemodynamic parameters } \\
\hline Heart rate (beats/min) & 90 [78-96] & 90 [77-103] & 92 [84-110] \\
\hline $\operatorname{CVP}\left(\mathrm{cmH}_{2} \mathrm{O}\right)$ & $13[10-16]$ & $12[9-17]$ & 19 [14-22] \\
\hline Mean PAP (mmHg) & 31 [24-37] & 38 [27-46] & $34[27-50]$ \\
\hline LVEF (\%) & 18 [15-22] & 16 [12-21] & 23 [18-32] \\
\hline Cardiac index $\left(\mathrm{L} \cdot \mathrm{min}^{-1} \cdot \mathrm{m}^{-2}\right)$ & $1.9[1.5-2.3]$ & $2.2[1.9-2.8]$ & $1.6[1.1-2.4]$ \\
\hline Required device, n (\%) & & $2 / 10 / 0$ & $3 / 4 / 2$ \\
\hline VA-ECMO & $1(7)$ & $2(18)$ & $3(50)$ \\
\hline IABP & $6(43)$ & $10(91)$ & $4(67)^{\#}$ \\
\hline RRT & $0(0)$ & $0(0)$ & $2(33)^{\#}$ \\
\hline Renal dysfunction (eGFR $<30$ or RRT), $n(\%)$ & $2(14)$ & $4(36)$ & $5(83)^{\#}$ \\
\hline \multicolumn{4}{|l|}{ Blood chemistry } \\
\hline Serum Cre (mg/dl) & $0.91[0.73-1.08]$ & $1.39[0.62-1.87]$ & $1.75[0.85-2.19]$ \\
\hline Serum bilirubin (mg/dl) & $1.7[1.0-2.8]$ & $1.3[0.8-3.0]$ & $1.2[0.7-6.0]$ \\
\hline \multicolumn{4}{|l|}{ Operation } \\
\hline Operation time (min) & $398[350-461]$ & $437[401-446]$ & $519[350-461]^{*}$ \\
\hline CPB time (min) & $140[112-170]$ & $157[141-203]$ & 179 [105-267] \\
\hline Fluid balance (ml) & $-1,290[-2,330$ to -228$]$ & $-790[-1,630$ to -210$]$ & $+1,402[168-2,315]^{*}$ \\
\hline Transfusion of red cell concentrate $(U)$ & $8[0-14]$ & $18[10-24]$ & $29[17-42]^{\star}, \S$ \\
\hline Transfusion of fresh frozen plasma $(U)$ & 7 [3-12] & $14[10-24]$ & $27[20-37]^{*}$ \\
\hline Transfusion of platelet concentrate $(U)$ & $20[0-20]$ & $20[20-40]$ & $45[40-65]^{\star, \S}$ \\
\hline \multicolumn{4}{|l|}{ Post-operative data } \\
\hline LVAD flow at $12 \mathrm{~h}(\mathrm{~L} / \mathrm{min})$ & $4.2[3.5-5.3]$ & $4.0[3.1-5.8]$ & $4.2[2.9-5.7]$ \\
\hline $\mathrm{CVP}$ at $12 \mathrm{~h}\left(\mathrm{cmH}_{2} \mathrm{O}\right)$ & $10[8-12]$ & $11[6-15]$ & $17[15-18]^{\star}, \S$ \\
\hline RVAD and/or NO, n (\%) & $1(7)$ & $2(18)$ & $3(50)$ \\
\hline ICU stay (day) & $6[5-10]$ & $13[10-17]^{*}$ & $44[17-69]^{\star}, \S$ \\
\hline 28-day mortality, n (\%) & 0 & 0 & $1(17)$ \\
\hline Total mortality, $\mathrm{n}(\%)$ & $1(7)$ & $1(9)$ & $4(67)^{\#}$ \\
\hline Recovery of cardiac function, $\mathrm{n}(\%)$ & $3(21)$ & $1(9)$ & $1(17)$ \\
\hline Heart transplantation, n (\%) & 0 & $4(36)$ & 0 \\
\hline
\end{tabular}

AKI, acute kidney injury; RRT, renal replacement therapy; DCM, dilated cardiomyopathy; HCM, hypertrophic cardiomyopathy; CVP, central venous pressure; PAP, pulmonary arterial pressure; LVEF, left ventricular ejection fraction; VA-ECMO, venoarterial extracorporeal membrane oxygenation; IABP, Intra-aortic balloon pump; eGFR, estimated glomerular filtration; Cre, creatinine; CPB, cardio-pulmonary bypass; LVAD, left ventricular assist device; RVAD, right ventricular assist device; NO, nitric oxide; ICU, intensive care unit.

${ }^{\#} \mathrm{P}<0.05$ Fisher's exact test for contingency table; ${ }^{*} \mathrm{P}<0.05$ vs. non-AKI; $\$ \mathrm{P}<0.05$ vs. AKI-without-RRT.

has demonstrated its clinical use in studies of both pediatric and adult post-cardiac surgery AKI cohorts, ${ }^{14-19}$ although no clinical evaluation of plasma NGAL on LVAD implantation has been reported to date. Although a previous report of ours study described a scoring system for predicting the prognosis after LVAD implantation, ${ }^{20}$ it involves no newly developed biomarkers such as NGAL.

This study was undertaken to evaluate whether plasma NGAL is predictive of renal dysfunction and poor outcome in patients who have undergone LVAD implantation surgery. Additionally, we assessed the putative role of plasma NGAL for predicting renal recovery in severe AKI patients who re- quired RRT. We also evaluated the performance of blood bilirubin concentration for predicting RRT requirement based on our previous report, in which the total bilirubin (TB) score and Cre score were able to predict persistent liver and renal failure after LVAD implantation. ${ }^{21}$

\section{Methods}

\section{Patient Population}

A total of 31 adult patients undergoing LVAD implantation at The University of Tokyo Hospital (Tokyo, Japan) during July 2011-March 2013 were studied prospectively. Outcomes such 
as total mortality were observed until March 2014. The observed period was 637 [483-797] days (median [interquartile]). The study protocol was approved by the Institutional Review Board. Informed consent was obtained from each participant. No chronic dialysis patient received LVAD implantation during the study period. Preoperative renal dysfunction was defined by either a requirement of RRT for acute decline of renal function or an estimated glomerular filtration rate (GFR) lower than $30 \mathrm{ml} \cdot \mathrm{min}^{-1} \cdot 1.73 \mathrm{~m}^{-2}$, as calculated using the Modification of Diet in Renal Disease (MDRD) equation with a known baseline Cre value (CKD stages 4 and 5).22 TB and Cre scores were calculated as follows: TB score $=0.15 \times$ age $+1.1 \times$ preoperative TB and Cre score $=0.2 \times$ age $+3.6 \times$ preoperative Cre. ${ }^{21}$ The presence of AKI was assessed by calculating the change in serum Cre from the baseline (before surgery) to the maximum serum Cre during the observational period of 7 days or a $0.3 \mathrm{mg} / \mathrm{dl}$ absolute increase within $48 \mathrm{~h}$ according to the Kidney Disease Improving Global Outcomes (KDIGO) guidelines. ${ }^{23}$ AKI was also diagnosed at initiation of RRT after surgery (stage 3 in the KDIGO AKI guidelines definition).

\section{Measurement of Plasma NGAL}

Plasma NGAL was determined using the Triage ${ }^{\circledR}$ NGAL Device (Alere Medical Co Ltd, San Diego, CA, USA), as described previously. ${ }^{14,24}$ Briefly, EDTA-anticoagulated whole blood was supplied to the assay device. The blood contained an NGALspecific monoclonal antibody conjugated to a fluorescent nanoparticle. The separated plasma reconstitutes the fluorescent antibody conjugate detection nanoparticles and flows down the diagnostic lane via capillary action. Quantitative measurements of NGAL concentration were conducted using a Triage Meter (Alere Medical Co Ltd), a portable fluorescence spectrometer.

Plasma NGAL measurements were conducted before LVAD implantation (pre), at ICU arrival ( $0 \mathrm{~h})$, and at 1, 7, 14, and 28 postoperative days for all patients. For 6 patients who required RRT after LVAD implantation, plasma NGAL was measured approximately every $24-96 \mathrm{~h}$.

Clearance of Cre and NGAL by Continuous Hemodiafiltration Blood and effluent fluid sampling was conducted for another cohort of 6 patients who were treated using post-dilution continuous hemodiafiltration (CHDF). These patients did not receive LVAD implantation but were in a critically ill condition with severe renal dysfunction.

Clearance of Cre and NGAL was calculated at 3, 12, and 24h after CHDF initiation as:

Clearance $=\underset{C f / C b}{[Q d}(\mathrm{ml} / \mathrm{min})+Q r(\mathrm{ml} / \mathrm{min})+$ Qnet $(\mathrm{ml} / \mathrm{min})] \times$

where $Q d$ represents the dialysate fluid rate, $Q r$ is the replacement fluid rate, Qnet is the net fluid removal rate (total ultrafiltration rate $=Q r+Q n e t$ ), and $C f$ and $C b$, respectively, denote the concentrations in the fluid (effluent fluid and dialysate) and blood obtained before hemofiltration.

Concentrations of Cre and NGAL in fluid were measured respectively using the Accuras Auto-Cre diagnosis kit (ShinoTest Corp, Tokyo, Japan) with an automatic clinical biochemical analyzer (JCA-BM2250; JEOL Ltd, Tokyo, Japan) and commercially available ELISA kits (NGAL ELISA Kit [KIT 036]; BioPorto, Gentofte, Denmark).

\section{Statistical Analyses}

Data were expressed as median [interquartile]. Continuous variables were compared using t-tests or Wilcoxon rank-sum

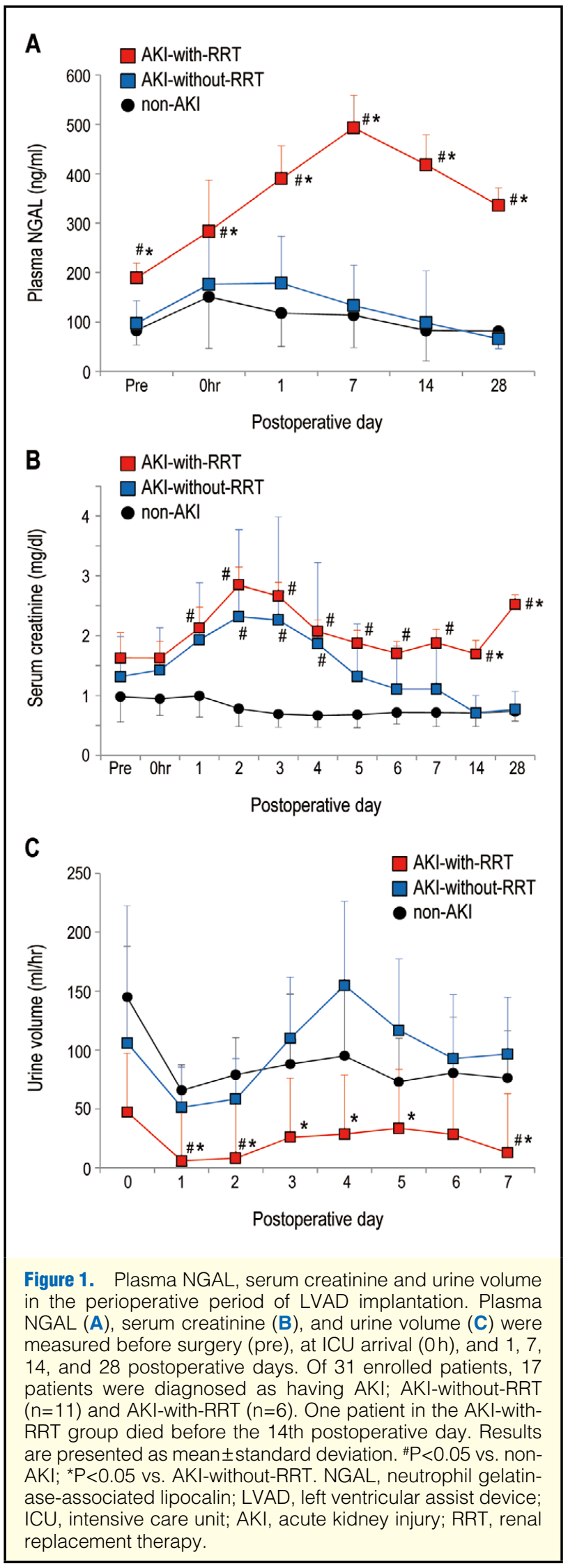


Table 2. ROC Analysis for RRT Requirement After LVAD Implantation

\begin{tabular}{lcccc} 
& AUC-ROC & Cut-off value & Sensitivity & Specificity \\
Plasma NGAL (pre) & $0.83[0.54-0.95]^{\#}$ & $103 \mathrm{ng} / \mathrm{ml}$ & $83 \%$ & $72 \%$ \\
Plasma NGAL (0h) & $0.86[0.66-0.95]^{\#}$ & $183 \mathrm{ng} / \mathrm{ml}$ & $100 \%$ & $68 \%$ \\
Serum Cre (pre) & $0.70[0.39-0.90]$ & $1.50 \mathrm{mg} / \mathrm{dl}$ & $67 \%$ & $76 \%$ \\
Serum Cre (0h) & $0.67[0.33-0.89]$ & $1.87 \mathrm{mg} / \mathrm{dl}$ & $67 \%$ & $88 \%$ \\
Cre socre & $0.77[0.40-0.95]$ & 16.9 & $67 \%$ & $100 \%$ \\
TB (pre) & $0.44[0.16-0.77]$ & $5.7 \mathrm{mg} / \mathrm{dl}$ & $100 \%$ & $56 \%$ \\
TB score & $0.78[0.57-0.91]^{\#}$ & 8.2 & $100 \%$ & $56 \%$ \\
CVP (pre) & $0.80[0.56-0.93]^{\#}$ & $19 \mathrm{~cm} \mathrm{H} \mathrm{O}$ & $67 \%$ & $88 \%$ \\
CVP at 12h & $0.89[0.70-0.97]^{\#}$ & $13 \mathrm{~cm} \mathrm{H} \mathrm{O}$ & $100 \%$ & $68 \%$ \\
Urine volume (0-6h) & $0.82[0.51-0.95]^{\#}$ & $22.8 \mathrm{ml} / \mathrm{h}$ & $67 \%$ & $96 \%$ \\
\hline
\end{tabular}

ROC, receiver operating characteristic; AUC-ROC, Area under the receiver operating characteristic curve; NGAL, neutrophil gelatinase-associated lipocalin; TB, total bilirubin. Other abbreviations as in Table 1.

Optimal cut-off values were determined using the Youden index (sensitivity+specificity-1), which represents the maximum potential effectiveness of a marker. ${ }^{\#} \mathrm{P}<0.05$.



tests when the normality assumption does not hold. A TukeyKramer or Steel-Dwass test was used for multiple comparisons. Categorical variables were compared using the Fisher's exact test. The urinary biomarker performance was assessed using receiver operating characteristic (ROC) curve analysis. Optimal cut-off values were ascertained using the Youden index (sensitivity + specificity -1 ), which is a common summary measure of the ROC curve representing the maximum potential effectiveness of a marker. ${ }^{25}$ These calculations were performed using software (JMP ver. 9.0; SAS Institute Inc). A conventional criterion of $\alpha=0.05$ was used to infer statistical significance.

\section{Results}

Patient Characteristics and Outcomes of LVAD Implantation Table 1 presents baseline clinical data, operation information, and outcomes of the enrolled patients. Of 31 LVAD implanted patients, AKI was diagnosed in 17 patients (55\%); RRT was needed in 6 patients after surgery (19\%). All these patients were treated initially using CHDF. Three of them were subsequently treated by intermitted hemodialysis (IHD). For 2 AKIwith-RRT patients, CHDF was started before surgery and stopped during the operation. Restarting CHDF after LVAD implantation was decided by surgeons and intensivists based on clinical data. Although dilated cardiomyopathy (DCM) is the most frequent cause of heart failure in this cohort, only 1 patient (17\%) in the AKI-with-RRT group suffered from DCM. Preoperative renal dysfunction was significantly more frequent in the AKI-with-RRT group than in the non-AKI and the AKIwithout-RRT groups. RRT-requiring AKI patients had significantly longer operation and cardiopulmonary bypass (CPB) times, a larger positive intraoperative fluid balance, more blood transfusion, a longer length of ICU stay, and a higher total mortality.

Six patients in this cohort died while being treated using LVAD. Three patients died of multiple organ failure and required RRT until death. The other 3 patients died of cerebral bleeding and/or infarction. Four patients received a heart transplantation an average of 665 days (480-867 days) after LVAD implantation.

\section{Plasma NGAL, Serum Cre, and Urine Volume in LVAD Implantation}

Figure 1 presents the perioperative values of plasma NGAL, serum Cre, and urine volume of each group. The AKI-withRRT group showed significantly higher plasma NGAL levels than either the AKI-without-RRT group or the non-AKI group (Figure 1A). In contrast, serum Cre levels of the AKI-withRRT and AKI-without-RRT groups were similar and higher than those of the non-AKI patients (Figure 1B). Urine volume showed similar patterns to those of plasma NGAL; only the AKI-with-RRT group showed a significantly lower urine output (Figure 1C). Univariate logistic regression analysis revealed plasma NGAL measured before surgery (pre) and at ICU arrival $(0 \mathrm{~h})$, urine volume for $6 \mathrm{~h}$ after ICU arrival, central venous pressure (CVP) measured before (pre) and $12 \mathrm{~h}$ after surgery. The preoperative TB score were significantly associated with postoperative RRT after LVAD implantation, although serum Cre and TB were not (Table 2). ROC analysis showed better prediction of plasma NGAL, CVP, and urine volume for the postoperative RRT requirement with the area under the ROC curve (AUC-ROC) above 0.80. Change of plasma NGAL between preoperative (pre) and ICU arrival ( $0 \mathrm{~h}$ ) 
Table 3. ROC Analysis for Renal Recovery After LVAD Implantation

\begin{tabular}{lcccc} 
& AUC-ROC & Cut-off value & Sensitivity & Specificity \\
Plasma NGAL (pre) & $0.67[0.44-0.84]$ & $65 \mathrm{ng} / \mathrm{ml}$ & $100 \%$ & $44 \%$ \\
Plasma NGAL (0h) & $0.74[0.51-0.88]^{\#}$ & $186 \mathrm{ng} / \mathrm{ml}$ & $83 \%$ & $68 \%$ \\
Plasma NGAL (1 POD) & $0.85[0.65-0.95]^{\#}$ & $215 \mathrm{ng} / \mathrm{ml}$ & $100 \%$ & $72 \%$ \\
Serum Cre (pre) & $0.81[0.55-0.94]^{\#}$ & $1.78 \mathrm{mg} / \mathrm{dl}$ & $83 \%$ & $84 \%$ \\
Serum Cre (0h) & $0.79[0.50-0.93]^{\#}$ & $1.43 \mathrm{mg} / \mathrm{dl}$ & $83 \%$ & $76 \%$ \\
Serum Cre (1 POD) & $0.79[0.49-0.94]$ & $1.58 \mathrm{mg} / \mathrm{dl}$ & $83 \%$ & $76 \%$ \\
\hline
\end{tabular}

POD, postoperative day. Other abbreviations as in Tables 1,2.

Optimal cut-off values were determined using the Youden index (sensitivity+specificity-1), which represents the maximum potential effectiveness of a marker. ${ }^{\#} \mathrm{P}<0.05$.

A



C

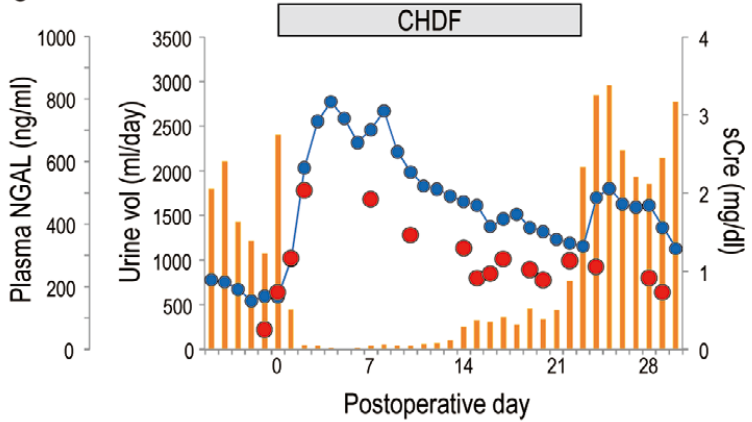

E

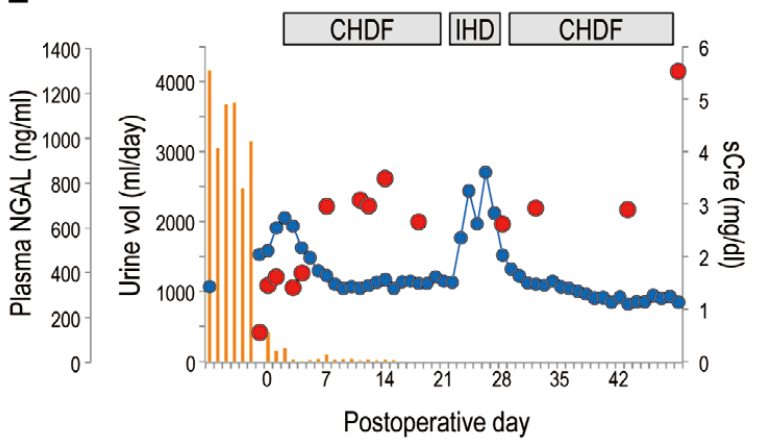

B



D



$\mathbf{F}$

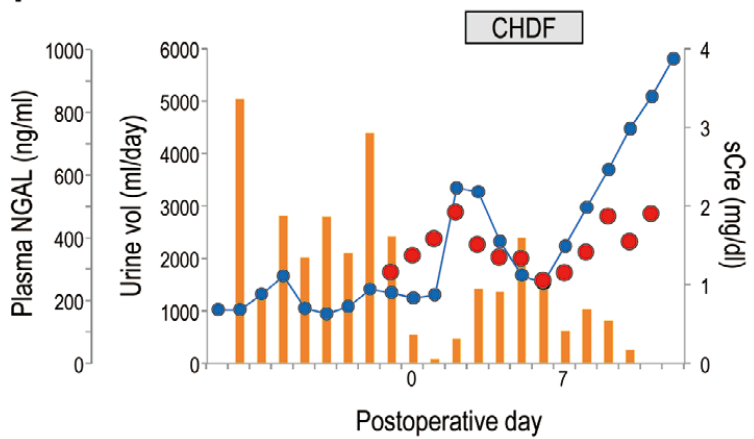

Urine volume

Plasma NGAL

Serum Cre

Figure 3. Clinical courses of the 6 patients from the AKI-with-RRT group. Four cases (Cases A-D) showed renal recovery. The other 2 cases (Cases $\mathbf{E}$ and $\mathbf{F}$ ) showed no renal recovery. Case $\mathbf{E}$ was treated by CHDF until death at 52 POD. CHDF was terminated because of an extremely unstable hemodynamic condition in Case F. AKI, acute kidney injury; RRT, renal replacement therapy; CHDF, continuous hemodiafiltration; POD, postoperative day. 


\begin{tabular}{|c|c|c|c|}
\hline & $3 \mathrm{~h}$ & $12 \mathrm{~h}$ & $24 \mathrm{~h}$ \\
\hline Serum Cre (mg/dl) & $3.3(1.9-4.0)$ & $3.2(1.8-3.3)$ & $2.9(1.7-3.5)$ \\
\hline Plasma NGAL (ng/ml) & $552(420-683)$ & $507(431-553)$ & $497(425-558)$ \\
\hline$Q d(\mathrm{ml} / \mathrm{min})$ & $10.0(10.0-10.0)$ & $10.0(10.0-10.0)$ & $10.0(10.0-10.0)$ \\
\hline Qr+Qnet $(\mathrm{ml} / \mathrm{min})$ & $6.9(6.7-8.0)$ & $7.8(6.8-8.3)$ & $7.9(7.3-8.3)$ \\
\hline
\end{tabular}

Clearance measurement for Cre and NGAL was conducted in 6 critically ill patients of another non-LVAD cohort at 3,12 , and $24 \mathrm{~h}$ after $\mathrm{CHDF}$ initiation.

CHDF, continuous hemodiafiltration; $Q d$, dialysate solution flow rate; $Q r$, replacement solution flow rate; Qnet, net fluid loss of each patient. Other abbreviations as in Tables 1,2.



among the groups were similar, indicating that LVAD implantation surgery itself might not improve or worsen kidney injury (Figure 2). Multiple logistic regression analysis incorporating the parameters that showed significant associations by univariate analysis demonstrated that not plasma NGAL $(0 \mathrm{~h})$, TB score (pre), and urine volume (0-6h), but plasma NGAL (pre) and CVP (pre and $12 \mathrm{~h}$ ) were independently associated with the postoperative RRT requirement after LVAD implantation (Likelihood ratio chi-squared for plasma NGAL 7.88 [P=0.005], CVP (pre) 5.26 [P=0.022], and CVP (12h) 5.99 $[\mathrm{P}=0.014])$.

\section{Plasma NGAL for the Prediction of Renal Recovery}

Three patients were treated with RRT until they died. The other three patients showed renal dysfunction, which was defined by an estimated GFR lower than $60 \mathrm{ml} \cdot \mathrm{min}^{-1} \cdot 1.73 \mathrm{~m}^{-2}$ at hospital discharge. Except for these 6 patients, all patients showed renal recovery. Plasma NGAL measured at 1 post operative day (POD) showed the highest AUC-ROC of 0.85 for predicting renal recovery (Table 3 ).

We further evaluated the performance of plasma NGAL in 6 AKI patients who needed RRT after LVAD implantation surgery (Figure 3). In Cases A and B, CHDF was started before LVAD implantation, whereas CHDF was initiated after surgery in Cases $\mathbf{C}$ and $\mathbf{D}$. In these 4 cases, urine volume began to increase after plasma NGAL decreased from its highest values. Serum Cre appeared to be changed by RRT and decreased gradually several days after cessations of RRT in Cases A,B, and C. Cases $\mathbf{E}$ and $\mathbf{F}$ did not have any renal recovery. Their plasma NGAL continued to increase, although serum Cre decreased by RRT. Case $\mathbf{E}$ was treated by $\mathrm{CHDF}$ until death at 52 POD, and CHDF was terminated because of an extremely unstable hemodynamic condition in Case $\mathbf{F}$.

\section{Removal of NGAL by CHDF}

Clearance measurements for Cre and NGAL were conducted in 6 critically ill patients from another non-LVAD cohort. Serum Cre and plasma NGAL in these patients (Table 4) were similar to those 6 LVAD patients (Figures 1,3). The doses of CHDF were comparable between these 2 cohorts (data not shown). Clearance calculation using blood and effluent fluid concentration revealed that Cre clearance by $\mathrm{CHDF}$ was virtually equal to $Q d+Q r+Q n e t$, and that NGAL clearance was approximately $25 \%$ below the Cre clearance (NGAL/Cre clearance ratio: 26 [23-34]\% at $3 \mathrm{~h}, 26$ [18-29]\% at $12 \mathrm{~h}$, and 22 [18-28]\% at 24h; Figure 4).

\section{Discussion}

This study evaluates the use of plasma NGAL measurement for post-LVAD implantation AKI and demonstrates that not serum Cre but plasma NGAL can predict the necessity of postoperative RRT requirement for AKI in LAVD implantation. A possible advantage of plasma NGAL over serum Cre in terms of predicting renal recovery under RRT is suggested by the data obtained from 6 RRT-treated AKI patients. Less removal of NGAL by CHDF compared with Cre was also demonstrated by clearance measurement.

Recently, several reports of clinical studies have described the significant impact of perioperative AKI on poor outcomes of LVAD implantation surgery. Sandner et al reported that the survival rate at 6 months post-LVAD implantation for AKI patients who required postoperative RRT was $29 \%$ vs. $78 \%$ for patients who were not treated by RRT. ${ }^{6}$ Other reports have also described significantly higher mortality of AKI patients after LVAD implantation than of non-AKI patients. ${ }^{26,27}$ It is noteworthy that postoperative AKI in LVAD implantation is reportedly associated with a higher mortality in the first year after surgery.,28 These observations underscore the necessity 
of innovative therapeutics against AKI to improve the LVAD implantation outcome.

Negative impacts of post-surgery AKI are not limited to LVAD implantation. Lassnigg et al reported a significant association of small serum Cre changes $(>0.5 \mathrm{mg} / \mathrm{L})$ with increased mortality in a large cardiac surgery cohort. ${ }^{8}$ Although a small Cre increase will predict adverse outcomes, the limitations of serum Cre for the early detection and accurate estimation of renal injury in AKI patients are well known. ${ }^{9}$ Therefore, the development of new AKI biomarkers has been emphasized recently to introduce more sensitive and accurate renal biomarkers to clinical use. Many clinical studies have evaluated emerging AKI biomarkers including NGAL, IL-18, KIM-1, and L-FABP with pediatric and adult post-cardiac surgery AKI cohorts. ${ }^{29-33}$ These biomarkers can predict AKI earlier than serum Cre can. Therefore, they are expected to enable earlier intervention against AKI and to promote the development of new drugs for use against AKI.

NGAL is a $25-\mathrm{kDa}$ protein covalently bound to neutrophil gelatinase $^{34}$ and NGAL mRNA is normally expressed in various adult human tissues, including bone marrow, stomach, colon, lung, liver, and kidney. ${ }^{35}$ Increased expression of NGAL in human AKI has been demonstrated. Blood and urinary NGAL protein levels in AKI patients were respectively 7-fold and 25-fold higher than healthy controls. However, patients with chronic kidney disease had less prominent elevations in blood and urine NGAL. ${ }^{36}$ Based on this finding, blood and urine NGAL have been evaluated in many clinical cohorts of AKI including post-cardiac surgery AKI, ${ }^{29}$ although no clinical study has evaluated the performance of NGAL in LVAD implantation. We report for the first time our demonstration that plasma NGAL is significantly associated with the risk of severe AKI requiring RRT in LVAD implantation. Actually, LVAD implantation has been increasing and is indicated not only for bridge to transplantation but also for destination therapy. Therefore, our findings are expected to prompt further investigations involving new AKI biomarkers in LVAD implantation.

In addition to plasma NGAL and urine volume, TB score and CVP were associated with the necessity of RRT (Table 2). Multiple logistic regression analysis revealed that only preoperative plasma NGAL and CVP were significantly associated with a RRT requirement. The absolute changes of plasma NGAL during LVAD implantation surgery were similar among the groups of non-AKI, AKI-without-RRT, and AKI-with-RRT (Figure 2). Although LVAD implantation is expected to provide hemodynamic stability and therefore improve renal function, ${ }^{3,37,38}$ it will potentially cause AKI as other cardiac surgeries do. ${ }^{6,26,27}$ The lack of differences of absolute changes of plasma NGAL irrespective of postsurgical AKI might be attributable to bidirectional effects of LVAD implantation. Transient renal ischemia, attributable to cardiac surgery with $\mathrm{CPB}$, might be cancelled out by subsequent improvement of renal perfusion by mechanical hemodynamic support. Preoperative plasma NGAL can identify the necessity of postoperative RRT after surgery because it might monitor renal structural damage, whereas serum Cre reflects not structural but functional damage of the kidney.

Reportedly, the complication of right ventricular failure had a significant effect on poor outcomes of LVAD patients, and higher CVP is a good predictor of right ventricular failure after LVAD implantation. ${ }^{39-41}$ In this study, not only plasma NGAL but CVP measured before and after the surgery were independently associated with RRT requirement. High CVP is associated with worsening renal function in decompensated heart failure patients. ${ }^{42}$ The combination of plasma NGAL and CVP might be useful for determining RRT initiation in LVAD implantation. In addition to AKI, liver dysfunction is another frequent perioperative end-organ dysfunction observed in LVAD patients. Although we previously reported the predictive value of the TB score for persistent liver dysfunction, which was observed 6 months after LVAD implantation, the TB score was not able to predict the postoperative RRT requirement better than plasma NGAL. Sepsis is the leading cause of AKI that occurred in ICU. However, the impacts of systemic infection and antibiotic usage on perioperative AKI in LVAD patients were unclear in this study. Further evaluation is reguined to clarify the influence of infection on postoperative AKI in LVAD implantation patients. ${ }^{43}$

In addition to earlier detection of AKI by NGAL than serum Cre, better prediction of renal recovery by new AKI biomarkers will be necessary. The only new biomarker study previously reported in the literature for discontinuation of RRT was conducted by Srisawat et al. ${ }^{44}$ They evaluated several urinary biomarkers in 76 ICU patients who developed AKI and who received RRT. Their results showed decreasing urinary NGAL and hepatocyte growth factor (HGF) in the first 14 days, which was significantly associated with renal recovery. Although the present study examined only 6 AKI patients treated with RRT, we observed the earliest peak of plasma NGAL that preceded the increase of urine volume. It is noteworthy that serum Cre appeared to be changed by RRT. Because of the much lower molecular weight of Cre compared with NGAL and the significantly higher removal efficacy by RRT, serum Cre will be influenced more easily by RRT than plasma NGAL. Further investigation is necessary to confirm our findings that plasma NGAL can predict renal recovery better than Cre can, even when the patients are treated by RRT.

Urine volume has been used clinically for determining the discontinuation of RRT for AKI. Uchino et al, from a multicentered, multi-national, prospective, epidemiologic study of AKI, reported that successful discontinuation of continuous RRT was associated significantly with urine output and serum Cre (area under the ROC curve 0.808 for urine output and 0.635 for $\mathrm{Cre}) .^{45}$ However, the prediction of renal recovery by urine output was negatively affected by diuretics in that study. We also observed significantly lower urine output in the AKIwith-RRT group in the present study. Urine volume $(0-6 \mathrm{~h})$ was associated with the RRT requirement after LVAD implantation. However, increased urine output appears to occur later than the decrease of plasma NGAL in 4 patients from the AKI-with-RRT group who eventually showed renal recovery in the present study.

Several limitations possibly affected the results obtained in this study. First, the number of patients $(n=31)$ is insufficient to ascertain the reliability and generalizability of plasma NGAL in LAVD implantation. Second, AKI was diagnosed by only measuring serum Cre. Although the AKIN criteria suggest the use of another criterion based on urine output, recent studies have frequently used the serum Cre-based criterion alone. ${ }^{46}$ Finally, no clear criteria were used for RRT indication. Although RRT has been used in AKI for more than 5 decades, no evidence-based standard criteria exist for starting and stopping RRT in AKI patients. Moreover, it remains unclear which AKI patients will need dialysis and who will recover renal function without requiring dialysis. ${ }^{47-52}$ Initiation and termination of RRT were judged by surgeons and intensivists based on clinically available information, which did not include plasma NGAL. Several factors including patient-specific and clinician-specific factors and those related to organi- 
zational/logistical issues might have influenced the decision of when to start and stop RRT.

\section{Conclusions}

Perioperative plasma NGAL measurement can predict severe AKI that requires RRT after LVAD implantation. In addition, renal recovery from RRT can be expected when plasma NGAL levels decrease, even when urine output appears to be insufficient. Advantages of plasma NGAL over serum Cre might derive partly from the lesser removal of NGAL by CHDF. Further investigation is necessary to confirm these findings because this study examined only a low number of patients.

\section{Acknowledgments}

Alere Medical Co Ltd (Tokyo, Japan) partly supported the collection and testing of blood samples, but did not contribute to the study design, data analysis, or preparation of the manuscript.

This study was partly supported by grants from the Tokyo Society of Medical Sciences (K.D.) and Asahi Kasei Kuraray Medical Co Ltd (E.N., K.D.).

\section{References}

1. Rose EA, Gelijns AC, Moskowitz AJ, Heitjan DF, Stevenson LW, Dembitsky W, et al. Long-term use of a left ventricular assist device for end-stage heart failure. N Engl J Med 2001; 345: 1435-1443.

2. Kirklin JK, Naftel DC, Kormos RL, Stevenson LW, Pagani FD, Miller MA, et al. Fifth INTERMACS annual report: Risk factor analysis from more than 6,000 mechanical circulatory support patients. $J$ Heart Lung Transplant 2013; 32: 141-156.

3. Butler J, Geisberg C, Howser R, Portner PM, Rogers JG, Deng MC, et al. Relationship between renal function and left ventricular assist device use. Ann Thorac Surg 2006; 81: 1745-1751.

4. Khot UN, Mishra M, Yamani MH, Smedira NG, Paganini E, Yeager $\mathrm{M}$, et al. Severe renal dysfunction complicating cardiogenic shock is not a contraindication to mechanical support as a bridge to cardiac transplantation. J Am Coll Cardiol 2003; 41: 381-385.

5. Kaltenmaier B, Pommer W, Kaufmann F, Hennig E, Molzahn M, Hetzer R. Outcome of patients with ventricular assist devices and acute renal failure requiring renal replacement therapy. ASAIO J 2000; 46: $330-333$.

6. Sandner SE, Zimpfer D, Zrunek P, Rajek A, Schima H, Dunkler D, et al. Renal function and outcome after continuous flow left ventricular assist device implantation. Ann Thorac Surg 2009; 87: $1072-1078$.

7. Yoshioka D, Sakaguchi T, Saito S, Miyagawa S, Nishi H, Yoshikawa $\mathrm{Y}$, et al. Predictor of early mortality for severe heart failure patients with left ventricular assist device implantation: Significance of INTERMACS level and renal function. Circ J 2012; 76: 1631-1638.

8. Lassnigg A, Schmidlin D, Mouhieddine M, Bachmann LM, Druml W, Bauer P, et al. Minimal changes of serum creatinine predict prognosis in patients after cardiothoracic surgery: A prospective cohort study. J Am Soc Nephrol 2004; 15: 1597-1605.

9. Star RA. Treatment of acute renal failure. Kidney Int 1998; 54: $1817-1831$.

10. Siew ED, Ware LB, Ikizler TA. Biological markers of acute kidney injury. J Am Soc Nephrol 2011; 22: 810-820.

11. Murray PT, Devarajan P, Levey AS, Eckardt KU, Bonventre JV, Lombardi R, et al. A framework and key research questions in AKI diagnosis and staging in different environments. Clin J Am Soc Nephrol 2008; 3: 864-868.

12. Coca SG, Yalavarthy R, Concato J, Parikh CR. Biomarkers for the diagnosis and risk stratification of acute kidney injury: A systematic review. Kidney Int 2008; 73: 1008-1016.

13. Noiri E, Doi K, Negishi K, Tanaka T, Hamasaki Y, Fujita T, et al. Urinary fatty acid-binding protein 1: An early predictive biomarker of kidney injury. Am J Physiol Renal Physiol 2009; 296: F669-F679.

14. Dent CL, Ma Q, Dastrala S, Bennett M, Mitsnefes MM, Barasch J, et al. Plasma neutrophil gelatinase-associated lipocalin predicts acute kidney injury, morbidity and mortality after pediatric cardiac surgery: A prospective uncontrolled cohort study. Crit Care 2007; 11: R127.

15. Koyner JL, Bennett MR, Worcester EM, Ma Q, Raman J, Jeevanandam $\mathrm{V}$, et al. Urinary cystatin $\mathrm{C}$ as an early biomarker of acute kidney injury following adult cardiothoracic surgery. Kidney Int 2008; 74: $1059-1069$.

16. Haase-Fielitz A, Bellomo R, Devarajan P, Story D, Matalanis G, Dragun D, et al. Novel and conventional serum biomarkers predicting acute kidney injury in adult cardiac surgery--a prospective cohort study. Crit Care Med 2009; 37: 553-560.

17. Tuladhar SM, Puntmann VO, Soni M, Punjabi PP, Bogle RG. Rapid detection of acute kidney injury by plasma and urinary neutrophil gelatinase-associated lipocalin after cardiopulmonary bypass. $J$ Cardiovasc Pharmacol 2009; 53: 261-266.

18. Haase M, Bellomo R, Devarajan P, Ma Q, Bennett MR, Mockel M, et al. Novel biomarkers early predict the severity of acute kidney injury after cardiac surgery in adults. Ann Thorac Surg 2009; 88: $124-130$.

19. Perry TE, Muehlschlegel JD, Liu KY, Fox AA, Collard CD, Shernan SK, et al. Plasma neutrophil gelatinase-associated lipocalin and acute postoperative kidney injury in adult cardiac surgical patients. Anesth Analg 2010; 110: $1541-1547$.

20. Imamura T, Kinugawa K, Shiga T, Endo M, Kato N, Inaba T, et al. Novel risk scoring system with preoperative objective parameters gives a good prediction of 1-year mortality in patients with a left ventricular assist device. Circ J 2012; 76: 1895-1903.

21. Imamura T, Kinugawa K, Shiga T, Endo M, Kato N, Inaba T, et al. Preoperative levels of bilirubin or creatinine adjusted by age can predict their reversibility after implantation of left ventricular assist device. Circ J 2013; 77: 96-104.

22. National Kidney Foundation. K/DOQI clinical practice guidelines for chronic kidney disease: Evaluation, classification, and stratification. Definition and classification of stages of chronic kidney disease. Am J Kidney Dis 2002; 39(2 Suppl 1): S46-S75.

23. KDIGO Acute Kidney Injury Work Group. Clinical practice guideline for acute kidney injury. Kidney Int 2012; Suppl 2: 1-138.

24. Katagiri D, Doi K, Matsubara T, Negishi K, Hamasaki Y, Nakamura $\mathrm{K}$, et al. New biomarker panel of plasma neutrophil gelatinase-associated lipocalin and endotoxin activity assay for detecting sepsis in acute kidney injury. J Crit Care 2013; 28: 564-570.

25. Ruopp MD, Perkins NJ, Whitcomb BW, Schisterman EF. Youden Index and optimal cut-point estimated from observations affected by a lower limit of detection. Biom J 2008; 50: 419-430.

26. Demirozu ZT, Etheridge WB, Radovancevic R, Frazier OH. Results of HeartMate II left ventricular assist device implantation on renal function in patients requiring post-implant renal replacement therapy. J Heart Lung Transplant 2011; 30: 182-187.

27. Hasin T, Topilsky Y, Schirger JA, Li Z, Zhao Y, Boilson BA, et al. Changes in renal function after implantation of continuous-flow left ventricular assist devices. J Am Coll Cardiol 2012; 59: 26-36.

28. Topkara VK, Dang NC, Barili F, Cheema FH, Martens TP, George I, et al. Predictors and outcomes of continuous veno-venous hemodialysis use after implantation of a left ventricular assist device. $J$ Heart Lung Transplant 2006; 25: 404-408.

29. Haase M, Bellomo R, Devarajan P, Schlattmann P, Haase-Fielitz A. Accuracy of neutrophil gelatinase-associated lipocalin (NGAL) in diagnosis and prognosis in acute kidney injury: A systematic review and meta-analysis. Am J Kidney Dis 2009; 54: 1012-1024.

30. Koyner JL, Parikh CR. Clinical utility of biomarkers of AKI in cardiac surgery and critical illness. Clin J Am Soc Nephrol 2013; 8: $1034-1042$.

31. Susantitaphong P, Siribamrungwong M, Doi K, Noiri E, Terrin N, Jaber BL. Performance of urinary liver-type fatty acid-binding protein in acute kidney injury: A meta-analysis. Am J Kidney Dis 2013; 61: $430-439$.

32. Arthur JM, Hill EG, Alge JL, Lewis EC, Neely BA, Janech MG, et al. Evaluation of 32 urine biomarkers to predict the progression of acute kidney injury after cardiac surgery. Kidney Int 2014; 85: $431-438$.

33. Liu Y, Guo W, Zhang J, Xu C, Yu S, Mao Z, et al. Urinary interleukin 18 for detection of acute kidney injury: A meta-analysis. Am J Kidney Dis 2013; 62: 1058-1067.

34. Kjeldsen L, Johnsen AH, Sengelov H, Borregaard N. Isolation and primary structure of NGAL, a novel protein associated with human neutrophil gelatinase. J Biol Chem 1993; 268: 10425-10432.

35. Cowland JB, Borregaard N. Molecular characterization and pattern of tissue expression of the gene for neutrophil gelatinase-associated lipocalin from humans. Genomics 1997; 45: 17-23.

36. Mori K, Lee HT, Rapoport D, Drexler IR, Foster K, Yang J, et al. Endocytic delivery of lipocalin-siderophore-iron complex rescues the kidney from ischemia-reperfusion injury. J Clin Invest 2005; 115: $610-621$.

37. Bank AJ, Mir SH, Nguyen DQ, Bolman RM 3rd, Shumway SJ, Miller LW, et al. Effects of left ventricular assist devices on outcomes in 
patients undergoing heart transplantation. Ann Thorac Surg 2000; 69: $1369-1374$.

38. Russell SD, Rogers JG, Milano CA, Dyke DB, Pagani FD, Aranda $\mathrm{JM}$, et al. Renal and hepatic function improve in advanced heart failure patients during continuous-flow support with the HeartMate II left ventricular assist device. Circulation 2009; 120: 2352-2357.

39. Kavarana MN, Pessin-Minsley MS, Urtecho J, Catanese KA, Flannery $\mathrm{M}, \mathrm{Oz} \mathrm{MC}$, et al. Right ventricular dysfunction and organ failure in left ventricular assist device recipients: A continuing problem. Ann Thorac Surg 2002; 73: 745-750.

40. Dang NC, Topkara VK, Mercando M, Kay J, Kruger KH, Aboodi MS, et al. Right heart failure after left ventricular assist device implantation in patients with chronic congestive heart failure. $J$ Heart Lung Transplant 2006; 25: 1-6.

41. Kormos RL, Teuteberg JJ, Pagani FD, Russell SD, John R, Miller LW, et al. Right ventricular failure in patients with the HeartMate II continuous-flow left ventricular assist device: Incidence, risk factors, and effect on outcomes. J Thorac Cardiovasc Surg 2010; 139: $1316-1324$.

42. Mullens W, Abrahams Z, Francis GS, Sokos G, Taylor DO, Starling $\mathrm{RC}$, et al. Importance of venous congestion for worsening of renal function in advanced decompensated heart failure. $J \mathrm{Am}$ Coll Cardiol 2009; 53: 589-596.

43. Uchino S, Kellum JA, Bellomo R, Doig GS, Morimatsu H, Morgera $\mathrm{S}$, et al. Acute renal failure in critically ill patients: A multinational, multicenter study. JAMA 2005; 294: 813-818.

44. Srisawat N, Wen X, Lee M, Kong L, Elder M, Carter M, et al. Urinary biomarkers and renal recovery in critically ill patients with renal support. Clin J Am Soc Nephrol 2011; 6: 1815-1823.

45. Uchino S, Bellomo R, Morimatsu H, Morgera S, Schetz M, Tan I, et al. Discontinuation of continuous renal replacement therapy: A post hoc analysis of a prospective multicenter observational study. Crit Care Med 2009; 37: 2576-2582.

46. Srisawat N, Hoste EE, Kellum JA. Modern classification of acute kidney injury. Blood Purif 2010; 29: 300-307.

47. Gibney N, Hoste E, Burdmann EA, Bunchman T, Kher V, Viswanathan $\mathrm{R}$, et al. Timing of initiation and discontinuation of renal replacement therapy in AKI: Unanswered key questions. Clin J Am Soc Nephrol 2008; 3: 876-880.

48. Gibney RT, Bagshaw SM, Kutsogiannis DJ, Johnston C. When should renal replacement therapy for acute kidney injury be initiated and discontinued? Blood Purif 2008; 26: 473-484.

49. Kellum JA, Mehta RL, Levin A, Molitoris BA, Warnock DG, Shah $\mathrm{SV}$, et al. Development of a clinical research agenda for acute kidney injury using an international, interdisciplinary, three-step modified Delphi process. Clin J Am Soc Nephrol 2008; 3: 887-894.

50. Cruz DN, Ricci Z, Bagshaw SM, Piccinni P, Gibney N, Ronco C. Renal replacement therapy in adult critically ill patients: When to begin and when to stop. Contrib Nephrol 2010; 165: 263-273.

51. Macedo E, Mehta RL. When should renal replacement therapy be initiated for acute kidney injury? Semin Dial 2011; 24: 132-137.

52. Clark E, Wald R, Walsh M, Bagshaw SM. Timing of initiation of renal replacement therapy for acute kidney injury: A survey of nephrologists and intensivists in Canada. Nephrol Dial Transplant 2012; 27: 2761-2767. 